\title{
The Effects of Climate Changes on The Distribution and Spread of Malaria in Sudan
}

\author{
Rasha A. Aal ${ }^{1}$, Ayman A. Elshayeb ${ }^{2, *}$ \\ ${ }^{1}$ Department of Environmental Studies, School of Life Sciences, Faculty of Science and Technology, \\ Alneelain University, Khartoum, Sudan \\ ${ }^{2}$ Department of Microbiology, College of Medical Laboratory Sciences. Karary University, Khartoum, Sudan
}

\begin{abstract}
Many diseases in Africa such as malaria are known to be sensitive to climate factors there is a positive correlation between malaria, cholera and meningitis, and climatic elements. Regular limits of malaria allocation indicate that malaria could develop for several months in most areas of Sudan due to climate variables. The study found that the malaria cases related to temperature increasing was clearly recognized in the Northern State with $1.59 \%$ out of the state population. The highest endemic state was Blue Nile with $2.45 \%$ in the Rich Wet Savannah, and the lowest state of malaria infections was Western Darfur with $0.06 \%$ cases. The total of malaria infections in northern Sudan is $15.19 \%$ of 29 million population, the prevalence of malaria in southern Sudan was $24.5 \%$ of 9.5 million population (including 2004 and 2005 returnees) of those examined were infected. Whilst in Khartoum State the mean number of cases increased to reach 60869 in the study period 5.5 million of population as the largest inhibited state.
\end{abstract}

Keywords Climate Changes, Malaria, Sudan, Temperature, Rainfall

\section{Introduction}

Climate is a major parameter in all ecosystems and has always been a fundamental factor in human settlement, economy and culture. Currently, world climate is in a warming phase that began in the early decades of the eighteenth century. Such changes are entirely natural, but there is evidence that in recent years a portion of the current warming may be attributable to human activities[1,2]. The potential impact of this global warming on human health is a major subject of debate[3,4]. Changes in climate factors "higher temperatures and heavier rainfall" and changes in climate variability would encourage insect carriers of some infectious diseases to multiply and move further[5].

Changes in climate may alter the distribution of important vector species and may increase the spread of disease to new areas- populations-that fall outside areas of stable endemic malaria transmission may be vulnerable to increases in malaria due to climate changes. Many of the diseases that currently occur in the tropics are mosquito borne[6]. It is a widely-held view that global warming and climate change affect infectious diseases such as malaria. With the high economic costs of malaria in Africa, it is expected that an increase in malaria incidence and prevalence could lead to an increase in poverty[7]. It is commonly assumed that mal-

* Corresponding author:

ayman_elshayeb@yahoo.com (Ayman A. Elshayeb)

Published online at http://journal.sapub.org/ajee

Copyright (C) 2011 Scientific \& Academic Publishing. All Rights Reserved aria distribution is determined by climate and that warmer global temperatures will increase their incidence and geographic range[8,9].

Sudan is characterized by a wide range of climate variation, which varies from desert in the northern, through Southward belt. Clearly, climatic factors play an important role in the transmission of malaria; regular limits of malaria allocation indicate that malaria could develop for several months in most areas of Sudan due to climate variables. Thus, An. gambiaecan survive in the Sudan (mean monthly temperatures of $42^{\circ} \mathrm{C}$; actual outdoor temperatures can be over $55^{\circ} \mathrm{C}$ ) by emerging after sunset, hiding in the thatch of buildings in the daytime, feeding after midnight, and ovipositing at dawn or dusk[10]. For example, in the severe drought and extreme heat of the dry season in semiarid parts of the Sudan, female An. gambiaesurvive up to 11 months of the year by resting in dwelling huts and other sheltered places. Blood feeding continues, so transmission not interrupted, but the ovaries do not begin to develop eggs until the rains return[11]. It has been stated that malaria fever and asthma have good correlation with some meteorological factors such as temperature, relative humidity and rainfall. Malaria was found to have strong correlation coefficients with both maximum and minimum temperatures, and strong positive correlation with air pressure[12].

Meteorological variables were the important environmental factors in the transmission of malaria globally. Spearman correlation analysis demonstrated relative humidity was greatest relative to malaria incidence. Strong positive correlations were found for malaria incidence time se- 
ries lagging one to three months behind rainfall $(\mathrm{r}>0.4)$ and lagging zero to two months behind temperature and relative humidity $(r>0.5)$ by the cross correlation[13]. The cross-correlograms between malaria incidence and various meteorological variables were entirely different. It was fluctuated randomly for temperature but with trend for the other two factors, which showed positive correlated to malaria when lag was from zero to 5 months and negative from 6 to 12 months. Besides, the inter-annual analysis showed strong correlation between differenced annual malaria incidence and differenced meteorological variables (annual average maximum temperature, annual average relative humidity and annual average rainfall[13]. Malaria was associated with rainfall and minimum temperature (with the strength of the association varying with altitude) in Ethiopia. Worrall and colleagues[14] used rainfall and maximum temperature at a lag of four months to successfully fit a biological transmission model to malaria case data in a district in Zimbabwe. Craig and colleagues[15] linked inter-annual differences in malaria to rainfall and temperature in South Africa. Sri Lanka has a long history of researching the links between rainfall and malaria and many studies observed links between the two[16,17]. Yet others did not find a strong[18] or an obvious correlation[19]. A study in Sri Lanka incorporating rainfall as a linear or nonlinear explanatory variable into a (seasonal) auto-regressive integrated moving average (ARIMA) model showed little improvement in malaria prediction over ARIMA models without a rainfall predictor[20].

Malaria, as the main cause of death and absence from work in Sudan, is the country's most important public health problem. Based on government records it causes deaths of about 35000 per year and represents the main cause of morbidity and mortality[21]. Annually, the number of malaria cases range between 7-8 million and malaria constitutes $30-50 \%$ of all outpatient attendance, $20-30 \%$ of all hospital admission and $5-15 \%$ of all deaths. However, experts believe that the magnitude of the malaria problem in Sudan far exceeds official figures, particularly in rural areas where access to appropriate health services (approximately $20 \%$ ) and epidemiological reporting systems are both very limited[22].

\section{Objectives}

This study was conducted in Sudan region to evaluate the direct and indirect effects of climate changes on malaria distribution and spread in the period $1997-2007$.

\section{Materials and Methods}

Climatic change scenarios required for endemic zones are temperature, rainfall and precipitation and their data was collected from the Sudan Meteorological Authority, to evaluate the effects of climate changes on malaria and mosquito spreading. The malaria records were used by the assist of the Ministry Health National Centre for Health Information.
Temporal correlations between malaria incidence and population of Sudan region were analyzed using several statistical methods. Spearman correlation analysis was conducted to examine the association between malaria epidemiology in Sudan states. Cross-correlation analysis of annual malaria incidence in 1997 to 2007 data time series revealed the time $\operatorname{lag}(\mathrm{s})$ showed strongest correlation.

\section{Results and Discussion}

\subsection{Change in Temperature and Rainfall}

Global atmospheric temperatures are presently in a warming phase that began 250-300 years ago. Speculations on the potential impact of continued warming on human health often focus on vectors transmitted diseases, namely malaria because of the strong correlation between the disease and climate variables. Elementary models suggest that higher global temperatures will enhance their transmission rates and extend their geographic ranges[23]. Increasing temperatures are estimated to progressively extend the distribution of malaria, also making the mosquito be able to colonize further. The results of Sudan temperature changes across climate this was indicated by[24], they are somewhat consistent and mostly in the range of 1 to $1.5^{\circ} \mathrm{C}$ warmer. Rainfall data have potential use for malaria prediction. However, the relationship between rainfall and the number of malaria cases is indirect and complex. The annual rainfall in Sudan varies from close to zero in arid zones to about 200 $\mathrm{mm}$ in tropical regions, but it has been declined by $15 \%$ in the last decades, (Figure 1).

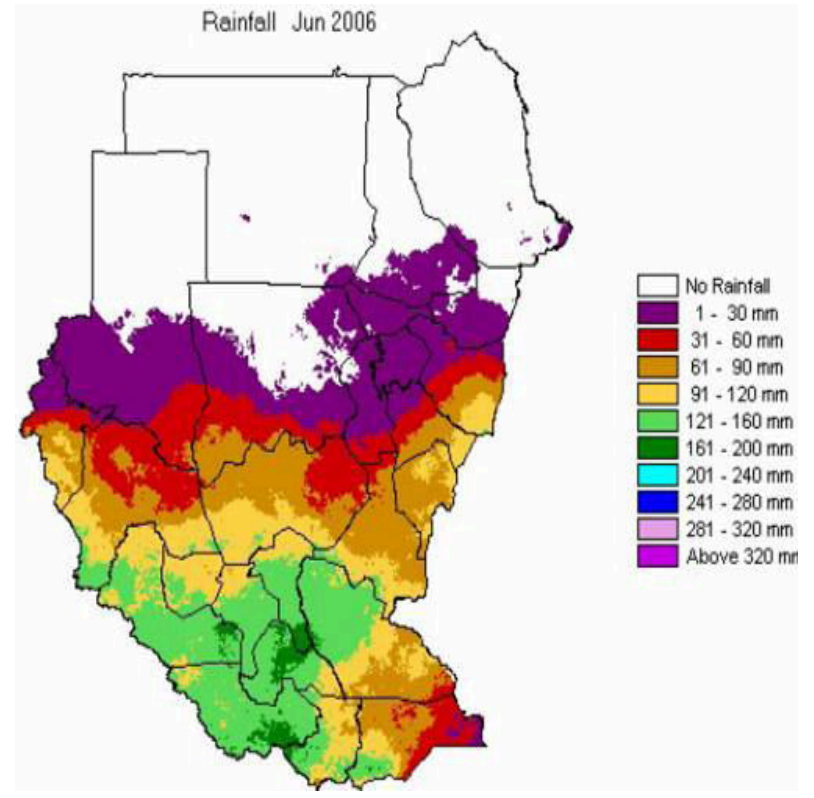

Source: Sudan Seasonal Monitor[25]

Figure 1. Rainfall distribution in Sudan.

\subsection{Distribution of Malaria Vector and Parasite in Sudan}

The distribution and abundance of vector organisms 
(disease carriers) and intermediate hosts are affected by both physical (e.g. temperature, humidity, rainfall) and biological factors (e.g. vegetation, host species, competitors, predators etc.) in the ecosystem. Changes in climate may alter the distribution of important vector species and increase the spread of diseases to new areas[26]. Climatic variations are thought to have a direct impact on the epidemiology of many vector-borne diseases, according to the World Health Organization, at least 30 diseases have emerged or resurged since $1975[27]$.

The diverse geographic landscapes and complex climate situations provide favorable breeding sites for mosquitoes in Sudan regions, Meteorological variables are considered as the environmental factors for increased risk of malaria because of their impacts on the mosquito vector activities and Plasmodium incubation rate. The main vector involved in transmission is the mosquito Anopheles arabiensis, which is well distributed over dry savannah and semi-arid parts of the country. Mosquitoes A. gambia and A.finistus are also sometimes involved, but Plasmodium falcipram is the main parasite for the majority of the infections $(90 \%)$ with other species $P$. vivax, $P$. ovale and $P$. malariae rarely found[26]. Malaria vectors are commonly found as high as $2,000 \mathrm{~m}$ above sea level, but pan endemic malaria disappears above $1,000-2,000 \mathrm{~m}$ in the Red Sea Mountains. All wet areas and rivers including River Nile are dominated by A. gambia andA. arabiensis. Survival rate may also be reduced when cold weather is accompanied by low humidity, but in areas where such conditions are normal, local species have adapted to cope with them. For example, in the severe drought and extreme heat of the dry season in semiarid parts of the Sudan, female Anopheles sp survive up to 11 months of the year by resting in dwelling huts and other sheltered places. Blood feeding continues, so transmission is not interrupted, but the ovaries do not begin to develop eggs until the rains return[10,11]. The effects of higher temperature on vector and parasite shorten the aquatic cycle of the mosquito from 20 to 7 days, matures faster, live longer, has more frequent blood meals and reduces the time between emergence and ovipositor, this increases the frequency of potential disease transmission in human populations[28].

\subsection{Distribution of Malaria Disease in Sudan}

Most areas of North Sudan are prone to malaria epidemics. A number of factors played role in them: increased rainfall spread of irrigated agriculture within the city limits, construction of new urban colonies without proper facilities for drainage, influx of refugees, insufficient supply of drugs[29].

Frequent epidemic were reported in Khartoum state, Gazira, Sinnar, White Nile, Blue Nile, Al- Gadarif, kassala, Red sea, Northern, River Nile, N. Darfour, W. Darfour, N. Kordfan stats (Figures 2,3). The main determinants of epidemics are: climatic factors, rains, floods, drought famine, spread of resistance of $P$. falciparum to chloroquine, increasing resistance of vectors to insecticides, migration of population from hypo to hyper endemic, instability in the bordering countries and refugees influx, establishment of large agricultural projects. Serious malaria epidemics affected the Gazira area in $1974-1975$ in the central region. Urban epidemics are well documented in Khartoum State in the years 1981, 1988, 1994, 1998. In Al- Gedarif State epidemic years usually follow heavy seasonal rains, 1993, 1998. An epidemic occurred in (1978) in this state following the war in Ethiopia and internally displaced people (IDPs) across the border to Kassala and Al - Gedarif states. Epidemics in River Nile State coincided with the heavy floods in 1974, $1988,1989,1994$. In the western part of the country, N. Kordofan two epidemics had been reported 1999 due to poor storage of water[29].

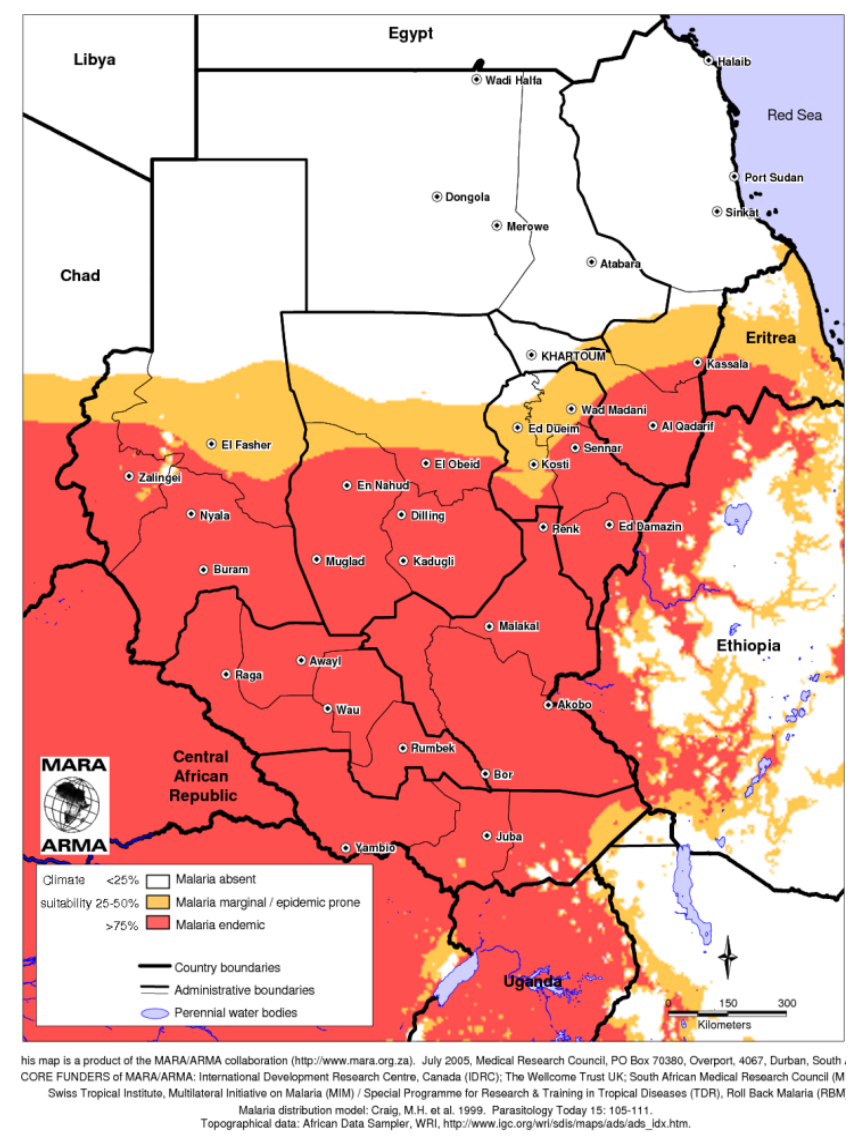

Source: MARA/ ARMA report[30].

Figure 2. Malaria distribution in Sudan.

A high fluctuation of malaria cases at species level was also observed with statistically significant $(\mathrm{p}<0.001)$ interannual variation of both P.vivax and P.falciparm malaria cases occurrence. With the exception of some years, a high predominance of $P$. falciparum over $P$. vivax was observed within the study period. Thus, the remarkable increment in total malaria cases was mainly due to the increment of $P$. falciparum rather than $P$. vivax. In the Blue Nile State, $P$. vivax was found to be highly diagnosed relative to $P$. falciparum, which indicates that currently there was a trend shift between $P$. falciparum and $P$. vivax malaria in the study area, (Figures 2,3).

Because of climatic and ecological diversity, there is 
variation in the epidemiology of transmission, ranging from hypo endemic in the desert fringe to unstable in poor savannah areas. Hyper endemic stable in rich savannah to high unstable endemic in urban areas, and intense, high transmission of the disease from endemic to pan endemic regions in the flood or rainy seasons (Table 1).

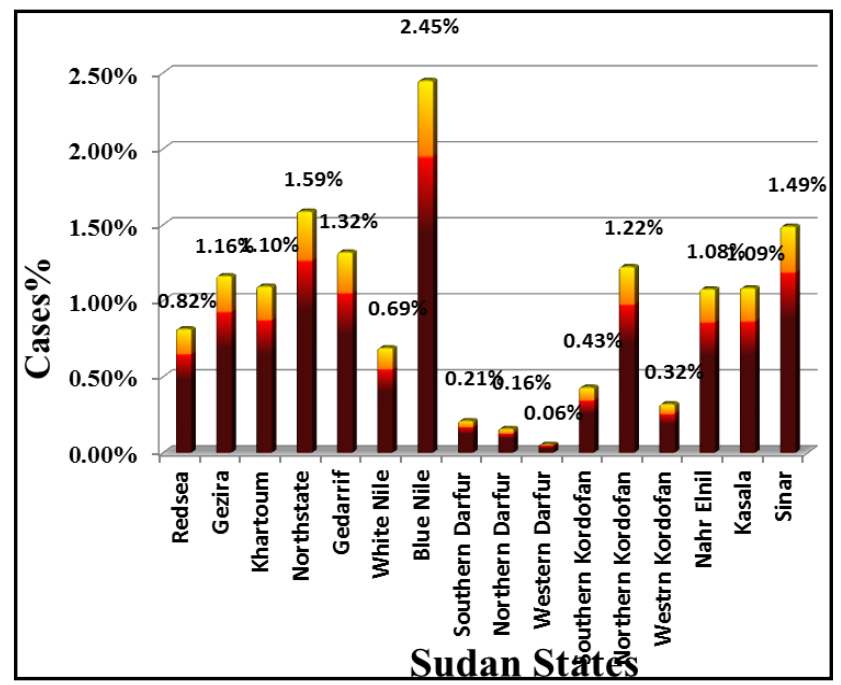

Figure 3. Malaria cases among Sudan States $1997-2007$.

The prevalence of malaria epidemiology in the human population of Sudan was studied (Table 1), Plasmodium falciparum was the common malaria parasite detected, even though records indicated presence of $P$. vivax. Malaria distribution is more closely to the rain distribution, this agreed with[31], who reported that the strong correlation between malaria epidemics and high rainfall has also been observed in most African countries.

Table 1. Malaria epidemiology in Sudan.

\begin{tabular}{|c|l|c|c|c|}
\hline Strata & Classification & $\begin{array}{c}\text { Annual } \\
\text { parasite } \\
\text { incidence }\end{array}$ & $\begin{array}{c}\text { Number of } \\
\text { population }\end{array}$ & $\begin{array}{c}\text { Malaria } \\
\text { intensity }\end{array}$ \\
\hline $\begin{array}{c}\text { Desert } \\
\text { fringe }\end{array}$ & Hypo-endemic & 3.8 & $1,000,000$ & Unstable \\
\hline $\begin{array}{c}\text { Poor } \\
\text { savannah }\end{array}$ & Meso-endemic & 4.8 & $20,000,000$ & Unstable \\
\hline $\begin{array}{c}\text { Rich wet } \\
\text { savannah }\end{array}$ & Hyper-endemic & 1.5 & $4,000,000$ & Stable \\
\hline $\begin{array}{c}\text { Urban } \\
\text { malaria }\end{array}$ & Meso-endemic & 0.3 & $5,000,000$ & Unstable \\
\hline
\end{tabular}

\subsection{Impacts of Malaria on Sudan Population}

Fifteen percent of the African population lives in the highlands and is at high risk from the impacts of epidemic malaria particularly in the eastern and southern African regions[32]. Complications due to malaria such as severe anemia (especially in children and pregnant women) and cerebral malaria are widespread posing a major health risk.

There is mounting evidence of long-term regional climate change in several parts of the country. This is witnessed by a very irregular decline in rainfall. The rainy seasons, rainy states and flood showed impacts of malaria distribution on the population with an exception of the Northern State. No significant values observed of the distribution of malaria among the Sudan region states. Whereas, the explanation of $\mathrm{P}>0.05$ indicates that there is an irregular spread of the disease through the country (Figure 3). The temperature impact was seen clearly in Northern State; meanwhile the rains affect the endemic parts of the country in the wet savannah and Southern States.

The annual admission records of malaria cases showed a significant relationship where $\mathrm{P}<0.05$ in the years 1997 2007. This explains the endemic status of the disease in this period with an exception of the years 2003 and 2006. The correlation of malaria cases per states showed annual trends of malaria cases in Sudan, 1997 - 2007, a fluctuating trend of malaria cases reported through the years 1997 to 2007 was observed. An increase in malaria cases occurrence in 2003 and 2006 with peak cases occurring in 2006 and malaria cases were reduced the following three consecutive years (2004 and 2007) but a remarkable increase in 2006 was observed, (Figure 4). During the study period, a total of $2,860,598$ cases were reported in Sudan with the annual mean number of 87411 malaria cases. The mean number of malaria cases occurrence in the study area was given by the leaner equation $y=190.96 x+68007$, this confirmed the stable situation of the disease in the same period (Figure 4).

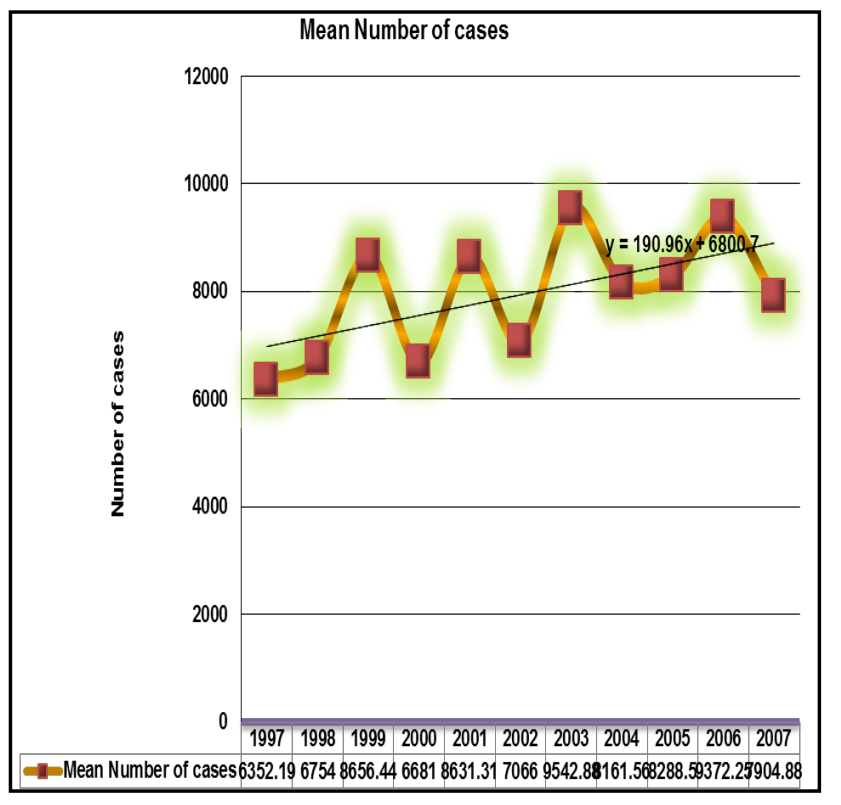

Figure 4. Mean number of malaria cases in Sudanese patients 1997 2007.

The statistical correlation between climate variability and some diseases has been investigated in scattered studies and reports in Sudan by[33] who found the relationship by using medical and meteorological data for six years (1986-1991) stated that malaria fever and asthma have good correlation with some meteorological factors. Malaria was found to have strong negative correlation coefficients with both maximum and minimum temperatures $(-0.7,-0.69$ respectively), and strong positive correlation with air pressure level (0.7)[33].

Based on climate models, it is estimated that $75 \%$ of the population (37 millions) are at risk of endemic malaria, while 
$25 \%$ are at risk of epidemic malaria. Most of the country below north latitude $15^{\circ}$ is endemic zone with high transmission in southern states, while parts of the north are exposed to epidemics following the heavy rains or floods from River Nile. Transmission of malaria in north Sudan from south regions is seasonal and depends on the rains except in urban cities and irrigated schemes. Sudan's rainy season lasts for about three months (July to September) in the north, and up to six months (June to November) in the south[29]. Two episodes of floods (2003 and 2006) witnessed the highest peaks of malaria increasing (Figure 2). Potential for climate changes induced malaria outbreak appears in the region even in the arid and semi-arid zones (due to increase of the Nile level during rainy season or due to local torrential rainfall), this was agreed with[26] who stated that flood events were found to cause malaria epidemics in Sudan. With climate change, extremes (drought, floods) are expected to increase in frequency, and accordingly malaria epidemics may increase. Malaria causes an enormous burden of morbidity in North Sudan, it represents around $21 \%$ of the outpatient consultations and around 30\% of inpatient admissions and the estimated malaria episodes 7.5 million. The prevalence of malaria among 2-10 years old children ranged between 0.7 to $20.9 \%$. The prevalence among $>5$ years children ranged between $0.4-15.5 \%$ and among the pregnant ranged between $3.7 \%-10.3 \%$. The rates are significantly higher in rural compared to urban population. With the high economic costs of malaria in Africa, it is expected that an increase in malaria incidence and prevalence could lead to an increase in poverty. For instance[34], have noted a five-fold difference between malarious and nonmalarious countries. Malaria causes considerable mortality in Sudan, especially among young children and pregnant women. In northern Sudan, $16 \%$ of hospital deaths are attributed to the disease. The case fatality rate of inpatient malaria cases is reported to be $2.5 \%$. Studies of individual hospitals in northern Sudan have found case fatality rates of between $5 \%$ and $12 \%$, with under-3 children four times more likely to die than others. Maternal malaria is a serious problem in Sudan, associated with maternal anemia and mortality, and with low birth weight newborns and perinatal mortality. Intermittent preventive treatment (IPT) was available in limited scale with a reported coverage of $22 \%$ in pregnant women. Complications due to malaria such as severe anemia (especially in children and pregnant women) and cerebral malaria are widespread posing a major health risk. Low birth weight caused by malaria is responsible for about 6 percent of infant mortality; for instance, in Kenya, malaria accounts for 40,000 infant deaths annually. Its eradication is linked to poverty alleviation despite the fact that it is at the same time a medical challenge. The impacts of malaria epidemics have been devastating and are increasingly exposing vulnerable groups to the adverse effects of climate change, as well as challenging their ability to cope. One of the critical factors influencing the vulnerability of human health to climate change is the extent to which the health and socio-economic systems are robust enough to cope (WHO, 2003).Malaria is also an economic burden, as it deprives
Africa of U.S\$ 12 billion every year in lost Gross Domestic Product (GDP)[35].

\section{Conclusions}

The study found that regular limits of malaria allocation could develop for several months with stable and unstable situation for many years in most areas of Sudan due to climate variables. We found that the malaria cases related to temperature increasing was clearly recognized in the Northern Sudan and cases related to rainfall is well recognized in Central and South east Sudan. The Western Sudan is the least endemic areas. Malaria transmission from endemic to pan endemic areas in Sudan is correlated with meteorological factors in different times of the year.

\section{ACKNOWLEDGEMENTS}

We would like to acknowledge with gratitude the Ministry Health National, Centre for Health Information. We appreciate the assistance that we received from the staff of the Statistic and Computer Department.

\section{REFERENCES}

[1] Houghton JT, MeiraFilho LG, Callander BA, Harris N, Kattenberg A, Maskell K, eds, (1996). The Science of Climate Change. Contribution of Working Group I to the Second Assessment of the Intergovernmental Panel on Climate Change (IPCC). Cambridge:Cambridge University Press

[2] Wigley TML, Schimel D, eds , (2000). The Carbon Cycle. Cambridge: Cambridge University Press

[3] Kerr RA., (1997). Greenhouse forecasting still cloudy. Science 276: 1040-1042

[4] Gubler DJ, (1998). Climate change: implications for human health. HlthEnv Digest 12:54-55

[5] Nkomo, J. C., Nyong A. O., and Kulindwa K, (2006).: The impacts of climate change in Africa, The Stern Review on the Economics of Climate Change

[6] Cook G, (1996). Manson's Tropical Diseases. London ed,:W.B. Saunders Co

[7] Cascio A, Bosilkovski M, et al. (2011). "The socio-ecology of zoonotic infections." ClinMicrobiol Infect 17(3): 336-42

[8] McMichael AJ, Haines A, Slooff R, Kovats S, (1996). Climate Change and Human Health. Geneva:World Health Organization (WHO)

[9] Watson RT, Zinyowera MC, Moss RH, (1998). The Regional Impacts of Climate Change: An Assessment of Vulnerability. Special Report of the Intergovernmental Panel on Climate Change (IPCC) Working Group II. Cambridge: Cambridge University Press

[10] Omer SM, Cloudsley-Thompson JL, (1970). Survival of 
female Anopheles gambiae Giles through a 9-month dry season in Sudan. Bull WHO:319-330

[11] Omer SM, (1968). Dry season biology of Anopheles gambiae Giles in the Sudan. Nature 217:879-880

[12] Idrees, S. H. (1992). A Study into the Occurrence of Some Common Diseases in Relationship with Some Atmospheric Variables in Khartoum. Institute of Environmental Studies. Khartoum,University of Khartoum

[13] Fang H., Shuisen Z., Shaosen Z., Hongju W.,and Linhua T., (2011). Temporal correlation analysis between malaria andmeteorological factors in Motuo County, Tibet. Malaria Journal, 10:54

[14] Teklehaimanot HD, Lipsitch M, Teklehaimanot A, Schwartz J, (2004): Weatherbased prediction of Plasmodium falciparum malaria in epidemic-prone regions of Ethiopia I. Patterns of lagged weather effects reflect biological mechanisms. Malar J, 3:41

[15] Worrall E, Connor SJ, Thomson MC, (2007): A model to simulate the impact of timing, coverage and transmission intensity on the effectiveness of indoor residual spraying (IRS) for malaria control. Trop Med Int Health, 12:75-88

[16] Craig MH, Kleinschmidt I, Nawn JB, Le Sueur D, Sharp BL, (2004): Exploring 30 years of malaria case data in KwaZulu-Natal, South Africa: part I. The impact of climatic factors. Trop Med Int Health, 9:1247-1257

[17] Rustomjee KJ, (1944): Observations upon the epidemiology of malaria in Ceylon. Volume XXIV- Colombo: Ceylon government press; 1944

[18] Mendis C, GamageMendis AC, De Zoysa AP, Abhayawardena TA, Carter R, Herath PR, Mendis KN, (1990): Characteristics of malaria transmission in Kataragama, Sri Lanka: a focus for immuno-epidemiological studies. Am J Trop Med Hyg, 42:298-308

[19] Abeku TA, de Vlas SJ, Borsboom G, Teklehaimanot A, Kebede A, Olana D, van Oortmarssen GJ, Habbema JD, (2002): Forecasting malaria incidence from historical morbidity patterns in epidemic prone areas of Ethiopia: a simple seasonal adjustment method performs best. Trop Med Int Health, 7:851-857

[20] Briët OJT, Vounatsou P, Gunawardena DM, Galappaththy GNL, Amerasinghe PH, (2008): Models for short term malaria prediction in Sri Lanka. Malaria J, 7:76

[21] PRSU (2004). Sudan, Interim Poverty Reduction Strategy Paper 2004-2006. Khartoum, Ministry of Finance and Na- tional Economy, Poverty Reduction Strategy Unit (PRSU)

[22] SFNC (2003). Sudan's First National Communications under the United Nations Framework Convention on Climate Change. Khartoum, Higher Council for Environment and Natural Resources: 94

[23] Paul R., (2001). Climate Change and Mosquito-Borne Disease. Environ Health Perspect 109(suppl 1):141-161

[24] Salih MA, Mohamed EF, et al. (1994). "Selenium in malnourished Sudanese children: status and interaction with clinical features." Ann NutrMetab 38(2): 68-74

[25] Sudan Seasonal Monitor, (2007) .Sudan Meteorological Authority Federal Ministry of Agriculture and Forestry Issue 6 November

[26] Ali H, H., Ahmed, S., and Sulaiman, S., (2008). Climate change and health in Sudan. Capacity strengthen in the least developed countries for adaptation to climate change

[27] World Health Organization (WHO). 1999. The World Health Report, 1999: Making a Difference. WHO, Geneva

[28] Afrane YA, Zhou G, et al. (2007). "Life-table analysis of Anopheles arabiensis in western Kenya highlands: effects of land covers on larval and adult survivorship." Am J Trop Med Hyg 77(4): 660-6

[29] Republic of the Sudan Federal Ministry of Health National Malaria Control Programme, (2006). National Strategic Plan for RBM 2007-2012. Khartoum

[30] MARA/ARMA, (1998). Towards an Atlas of Malaria Risk in Africa; Albany Print Ltd.: Durban, South Africa; pp. 1-31

[31] Githeko AK, Lindsay SW, et al. (2000). "Climate change and vector-borne diseases: a regional analysis." Bull World Health Organ 78(9): 1136-47

[32] Worrall E, Rietveld A, Delacollette C. 2004. The burden of malaria epidemics andcosteffectiveness of interventions in epidemic situations in Africa. Am J Trop Med Hyg. 1(2 Suppl):136-40

[33] Idrees, S. H. (1992). A Study into the Occurrence of Some Common Diseases in Relationship with Some Atmospheric Variables in Khartoum. Institute of Environmental Studies. Khartoum, University of Khartoum

[34] Sachs, J and Malaney, P (2003): The economic and social burden of malaria, Nature,Vol. 415, 680 - 685

[35] Greenwood, B. (2004). Between hope and a hard place. Nature, 430:926-927 